\title{
Airway Management and Ventilator-Associated Events
}

\author{
Amanda M Dexter and J Brady Scott
}

\author{
Introduction \\ Terminology \\ Ventilator-Associated Pneumonia \\ Ventilator-Associated Events \\ Prevention of Ventilator-Associated Events \\ Airway Management \\ Endotracheal Tube Suctioning \\ Endotracheal Tube Cleaning \\ Subglottic Secretion Drainage \\ Optimizing Cuff Pressures \\ Conclusions
}

\begin{abstract}
Airway management techniques are aimed at reducing complications associated with artificial airways and mechanical ventilation, such as retained secretions. The impact of airway management techniques on ventilator-associated events (VAEs) varies considerably by modality. Closed-suction techniques are generally recommended but have limited, if any, impact on VAEs. Normal saline instillation during suctioning is not recommended. Devices designed specifically to remove biofilm from the inside of endotracheal tubes appear to be safe, but their role in VAE prevention is uncertain. Subglottic secretion clearance by artificial cough maneuvers is promising, but more research is needed to assess its clinical feasibility. Continuous cuff-pressure management appears to be effective in reducing microaspiration of subglottic secretions. Key words: airway management; ventilator-associated event; mechanical ventilation; ventilator-associated pneumonia; suctioning; biofilm; subglottic drainage; cuff pressure. [Respir Care 2019;64(8):986-993. () 2019 Daedalus Enterprises]
\end{abstract}

\section{Introduction}

Airway care is a critical component of the management of acute and chronically ill patients who are mechanically

\footnotetext{
Ms Dexter is affiliated with the Department of Kinesiology, Respiratory Care Program, University of North Carolina at Charlotte, Charlotte, North Carolina. Mr Scott is affiliated with the Department of Cardiopulmonary Sciences, Division of Respiratory Care, Rush University, Chicago, Illinois.

Mr Scott presented a version of this paper at the New Horizons in Respiratory Care Symposium: Ventilator Associated Events - Surveillance and Understanding at the AARC Congress 2018, held December 4-7, 2018, in Las Vegas, Nevada.
}

Mr Scott has disclosed a relationship with Ventec Life Systems. Ms Dexter has disclosed no conflicts of interest. ventilated. Failure to properly manage an artificial airway can result in retained secretions, airway obstructions, and infection. ${ }^{1-3}$ These can lead to complications that may prolong duration of mechanical ventilation, ICU length of stay, and hospital length of stay, and may increase costs as well., ${ }^{4,5}$ Efforts have been made over the years to improve and evaluate airway management techniques. Many of these efforts sought to understand the role of airway management

\footnotetext{
Correspondence: J Brady Scott MSc RRT RRT-ACCS AE-C FAARC, Rush University, Department of Cardiopulmonary Sciences, Division of Respiratory Care, Armour Academic Center, 600 S Paulina St, 751 AAC, Chicago, IL 60607. E-mail: jonathan_b_scott@rush.edu
}

DOI: $10.4187 /$ respcare.07107 
techniques and their impact on ventilator-associated pneumonia (VAP) and ventilator-associated events (VAEs).

VAEs are common complications in patients receiving mechanical ventilation in the ICU.1,2,6 The prevention of VAEs has received much attention due to the associated increase in morbidity and mortality among mechanically ventilated patients. ${ }^{7}$ Techniques such as artificial airway suctioning, removal of biofilm, subglottic secretion drainage, and cuff management have been described in the literature as ways to reduce VAEs. This paper will review each of these techniques and their known impact on VAEs in mechanically ventilated patients.

\section{Terminology}

\section{Ventilator-Associated Pneumonia}

Prior to 2013, the Centers for Disease Control and Prevention (CDC) and a collaborative effort between the American Thoracic Society (ATS) and the Infectious Disease Society of America (IDSA) provided surveillance definitions for VAP. ${ }^{7-12}$ The CDC defined VAP as hospitalacquired pneumonia occurring within the 48-h period following endotracheal intubation. ${ }^{2-3,11,13-14}$ The ATS/IDSA defined VAP as hospital-acquired pneumonia occurring $>48-72 \mathrm{~h}$ after endotracheal intubation. ${ }^{11,12}$ While their combined initial goals were to maximize clinical correlation and improve objectivity of VAP surveillance, the timeline differences were significantly problematic for clinicians and institutions that attempted to make comparisons between institutional VAP rates and benchmarks. ${ }^{11,12} \mathrm{It}$ also allowed for high clinician variability and uncertainty in VAP interpretations. ${ }^{11,12}$

Another difficulty with these VAP definitions was that they required radiographic findings. Past evidence has suggested that radiographic findings do not correctly identify VAP. ${ }^{15}$ Furthermore, the reliance on clinical signs and symptoms were not only highly subjective, but also poorly documented. ${ }^{15-18}$ Even with a general consensus regarding morbidity, excess health care costs, and the need to prevent VAP, disagreement continued to exist about definitions and approaches for its prevention.

\section{Ventilator-Associated Events}

Several concerns invoked the shift to VAEs. From a clinician's perspective, the VAP criteria were demanding. In early 2013, the focus switched from VAP to $\mathrm{VAE}$ in response to increasing concerns regarding the appropriateness of traditional definitions in meeting the needs of quality-improvement projects and benchmarking proposals. ${ }^{8-10,19-22}$ The VAE algorithm includes a set of definitions designed to detect both infectious and noninfectious complications as well as direct and indi- rect consequences of mechanical ventilation. ${ }^{8-10,19,20,22-24}$ This surveillance approach consists of 3 tiers of definitions: Tier 1, ventilator-associated conditions (VACs); Tier 2, infection-related ventilator-associated complications (IVACs); and Tier 3, possible and probable VAP (Fig. 1). ${ }^{8-10,19,20,23,24}$

The core definition in the VAE framework is VAC, which detects respiratory deterioration following at least $2 \mathrm{~d}$ of ventilator setting stability or improvement. Subsets of VACs can be identified through additional criteria attributable to pneumonia or other infections. ${ }^{8-10,15,19,22,24}$ An IVAC is a concurrent inflammatory change and treatment course adjustment in a patient with a VAC. The last tier of the VAE algorithm, possible/probable VAP, is a subset of IVACs with positive respiratory cultures. ${ }^{8-10,15,19,22,24,25}$

$\mathrm{VAE}$ is now the formal terminology used to describe all the complications that can occur in mechanically ventilated patients. While this comprehensive definition is beginning to emerge clinically, the terminology lags in the literature. To date, few studies define these adverse events as VAEs, and several still default to using the term VAP. To impact patient outcomes, clinicians must strive to identify the differences between these definitions, highlight the correlations, and develop a clear sense of the extent to which global VAE prevention strategies can improve outcomes for ventilated patients.

\section{Prevention of Ventilator-Associated Events}

It is estimated that $>300,000$ patients per year receive mechanical ventilation in the United States, with VAEs consistently having a high morbidity and mortality prevalence. ${ }^{2,11,26-32}$ The number of patients on a mechanical ventilator who develop a VAE is estimated to be 5-40\% of all patients, and some studies have reported a mortality risk increase of nearly 50\%.26-29,33-35 VAEs have also been shown to lengthen the duration of hospitalization by an average of 7-9 d per patient. ${ }^{33,34}$

VAE onset is another important variable that clinicians must consider. Early-onset infections (ie, occurring within the first $4 \mathrm{~d}$ of hospitalization) compared to late-onset infections (ie, $\geq 5$ d) typically carry a better prognosis. ${ }^{7,11-12,36}$ The average time to VAE onset is 5-6 d. ${ }^{37-39}$

Additionally, VAEs have been shown to increase health care costs by an estimated $\$ 12,000-\$ 40,000$ per episode. ${ }^{33,40}$ In 2013 , Zimlichman et $\mathrm{al}^{41}$ found that VAEs are among the most costly infections in the ICU environment, resulting in the second greatest contributing factor $(31.6 \%)$ to overall health care costs. Consequently, strategies to reduce time on the ventilator have been encouraged, but for those who must remain intubated, proper airway care is crucial to minimizing devastating side effects and preventing a VAE. ${ }^{2,42,43}$ 


\section{VAE: Ventilator-Associated Event}

Designed to detect both infectious and noninfectious complications

Identify direct and indirect consequences of mechanical ventilation

VAC: Ventilator-Associated Condition

New respiratory deterioration

$\geq 2 \mathrm{~d}$ of ventilator stability

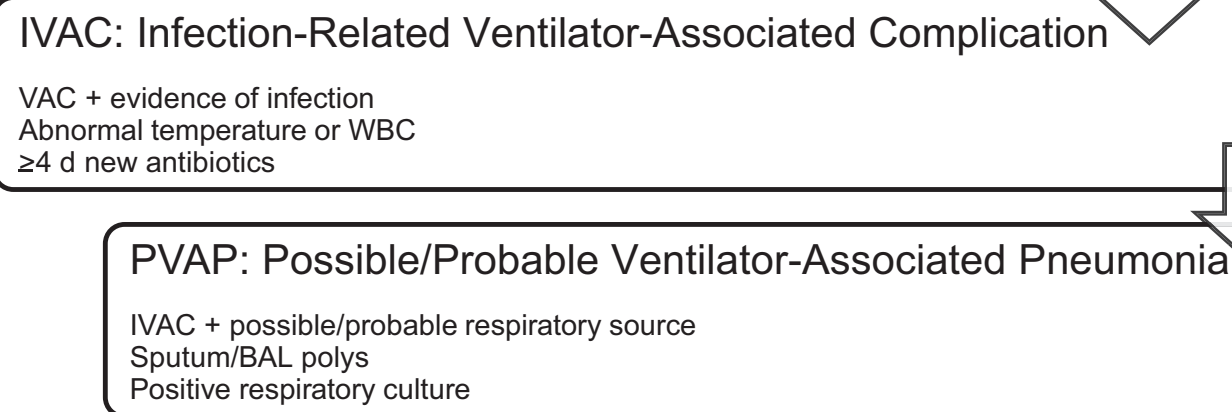

Fig. 1. Ventilator-associated events framework from the Centers for Disease Control and Prevention. WBC $=$ white blood cell, BAL $=$ bronchoalveolar lavage. Adapted from Reference 24.

Evidence suggests that once invasive ventilation is initiated, VAE prevention is key. ${ }^{42,43}$ A logical strategy to VAE prevention is to select interventions that reduce mechanical ventilation duration and hence the length of time a patient is at risk for VAEs. Both observational and interventional studies have suggested that a large percentage of VAEs are preventable and influenced by airway management., 7,27,30

\section{Airway Management}

One of the fundamental roles of a respiratory therapist is management of the artificial airway. Airway management is defined as the evaluation, planning, and use of medical practices and devices for the purpose of preserving or reestablishing ventilation in an intubated patient. ${ }^{43}$ Once the patient is intubated, the initial airway management concern is securing the endotracheal tube (ETT). ${ }^{43}$ There are a number of means for securing the tube to prevent unplanned removal or inadvertent migration, which can lead to severe consequences, such as microaspiration and airway injury. ${ }^{43}$ Available devices range from simple adhesive tape to those that use Velcro, adjustable straps, bite blocks, and skin-protective materials. ${ }^{43}$ A series of trials have evaluated various ETT stabilization devices, but it is not yet known which device or method is superior. ${ }^{43}$ In addition to ETT stabilization, the literature suggests measures in the prevention of VAEs be directed toward process improvement strategies targeting different modifiable airway management competencies, includ- ing suctioning, ETT cleaning, subglottic drainage, and ETT cuff-pressure management. ${ }^{27}$

\section{ETT Suctioning}

Mucociliary clearance is compromised following endotracheal intubation and mechanical ventilation. ETT suctioning is the standard of care in an ICU environment for intubated patients, with the primary goal being mucus removal and maintenance of airway patency. ${ }^{3}$

Open versus Closed Suctioning. ETT suctioning includes both open- and closed-circuit suctioning techniques. ${ }^{43}$ In the past, while open-circuit suctioning was common, it frequently resulted in both hemodynamic instability and hypoxemia. ${ }^{43}$ Over the years, numerous cited advantages, including improved oxygenation, PEEP maintenance, and decreased contamination exposure, have assisted in making closed-circuit suctioning a common airway management practice..$^{3,43,44}$ Despite their prevalent use in the ICU, in-line suction catheters (ie, a closed-suction system) historically have never been shown to decrease VAP rates. ${ }^{44}$

In 2003, Stoller et $\mathrm{al}^{44}$ assessed the impact of weekly versus daily changes of in-line suction catheters on both VAP frequency and equipment costs. An observational study was conducted comparing a 3-month control period in which daily in-line suction catheter changes were done to a 3-month treatment period in which weekly (or more frequently) in-line 
suction catheter changes were completed. ${ }^{44}$ Similar to previous studies, despite substantial cost savings, they noted no significant difference in VAP frequency, ICU length of stay, or ICU readmission rates between the 2 groups. ${ }^{44}$ Thus, decreasing the occurrence of routine suction equipment changes is safe and cost-effective. ${ }^{44}$

Also in 2003 , Zeitoun et al ${ }^{45}$ conducted a prospective, randomized study to evaluate VAP incidence in patients with prolonged mechanical ventilation who underwent open- versus closed-suction methods. Forty-seven subjects were divided into an open group $(n=24)$ and a closed group $(n=23){ }^{45}$ The authors reported no statistically significant difference in the prevalence of VAP development between the 2 groups, (11 of 25 subjects vs 7 of 23 subjects, $P=.28$, respectively). ${ }^{45}$ They concluded that although a closed-suction system did not prevent the onset of pneumonia, the prevalence of multiple external risk factors increased the probability. 45

In 2004 Dodek et $\mathrm{al}^{35}$ developed an evidence-based guideline for VAP prevention. A VAP Prevention Guideline Panel was formed, consisting of 9 intensivists, a critical care nurse, and an ICU respiratory therapist. ${ }^{35}$ The panel's conclusions had 3 major findings: the type of suction system had no effect on the incidence of VAP, scheduled daily changes and unscheduled changes of closed suctioning systems had no influence on VAP rates, and cost considerations favored closed suctioning systems. ${ }^{35}$

In 2010, the American Association for Respiratory Care (AARC) published their clinical practice guideline pertaining to endotracheal suctioning of mechanically ventilated patients. ${ }^{46}$ The recommendations made in that guideline suggested performing suctioning without disconnecting the patient from the ventilator. The guideline also recommended closed suctioning in patients with high $\mathrm{F}_{\mathrm{IO}_{2}}$ or PEEP settings and for patients at risk for lung de-recruitment. ${ }^{46}$ These recommendations were based on physiologic consequences of suctioning (eg, decreased oxygen saturations, changes in heart rate) and not to prevent VAEs. ${ }^{46}$ These recommendations have been supported in the literature. Maggiore et $\mathrm{a}^{47}$ also developed guidelines for ETT suctioning to be used in their institution. Elements of the guideline included, among other points, avoidance of ventilator disconnection and the use of closed suctioning. After implementation of their guidelines, they noted an overall decrease in suction-related complications from $59.5 \%$ to $42.6 \%(P<.05)$, with a $40 \%$ decrease in oxygen desaturation as an adverse event. The authors noted that adverse effects related to suctioning, such as oxygen desaturation, could be reduced by guideline implementation. ${ }^{47}$

In 2018, Letchford and Bench ${ }^{3}$ attempted to determine the most effective suctioning method in the prevention of VAP. They evaluated articles that were published between January 2009 and 2016. In the 2 studies that compared closed-suction systems with open-suction systems, neither study reported the superiority of closed systems in the prevention of earlyonset VAP. However, one of the studies did support closedsuction systems to prevent late-onset VAP.,3,48

Instillation of Normal Saline for Suctioning. The practice of instilling normal saline during suctioning is controversial because it is known to cause severe coughing episodes, hypoxemia, hypertension, bronchospasm, and dislodgement of bacterial biofilm colonized in the ETT into the lower airway. ${ }^{43,46}$ The potential benefits of normal saline instillation (eg, thinning of tracheobronchial secretions) have not been well documented. The 2010 AARC clinical practice guidelines recommended against the routine use of normal saline prior to ETT suctioning. ${ }^{46}$

In 2014, Caparros and Forbes ${ }^{49}$ performed a comprehensive review of the literature to determine if normal saline instillation during suctioning was beneficial or harmful. Their findings suggested that normal saline instillation during suctioning could lead to VAP and negative hemodynamic changes. Interestingly, they noted that no studies demonstrated any benefit of normal saline instillation during suctioning. ${ }^{49}$ The authors did not endorse normal saline instillation during suctioning, but did admit that there needs to be more, welldesigned studies examining the issue further.

In 2017, Wang et al ${ }^{50}$ conducted a systematic review to assess the need for normal saline instillation prior to suctioning ICU patients. Five randomized, controlled trials were evaluated, and 3 cardiopulmonary parameters (ie, oxygen saturation, heart rate, and blood pressure) were assessed as primary and secondary outcomes. ${ }^{50}$ Whereas the heart rate and blood pressure values showed no differences between the group that underwent normal saline instillation and the group that did not receive saline instillation, oxygen saturation levels were significantly lower in the group that received normal saline instillation. ${ }^{50}$ The authors concluded that normal saline instillation does not benefit patients during suctioning. The authors also suggested that well-designed studies were needed to further examine this issue, citing poor methodological quality of the studies currently available..$^{50}$ In 2014, Branson et al ${ }^{43}$ suggested that normal saline instillation during suctioning was, at best, unsupported and perhaps even dangerous. It appears that this remains true today.

\section{ETT Cleaning}

Biofilm. Biofilm growth on medical devices has received a significant amount of attention over the last few years because such growth has been shown to contribute up to $80 \%$ of resistant infections in hospitals. ${ }^{51,52}$ Specific to ICU patients who require artificial airways, bacterial and fungal biofilms have been associated with VAP and catheter-associated infections. ${ }^{53}$ Infections related to biofilms pose significant 

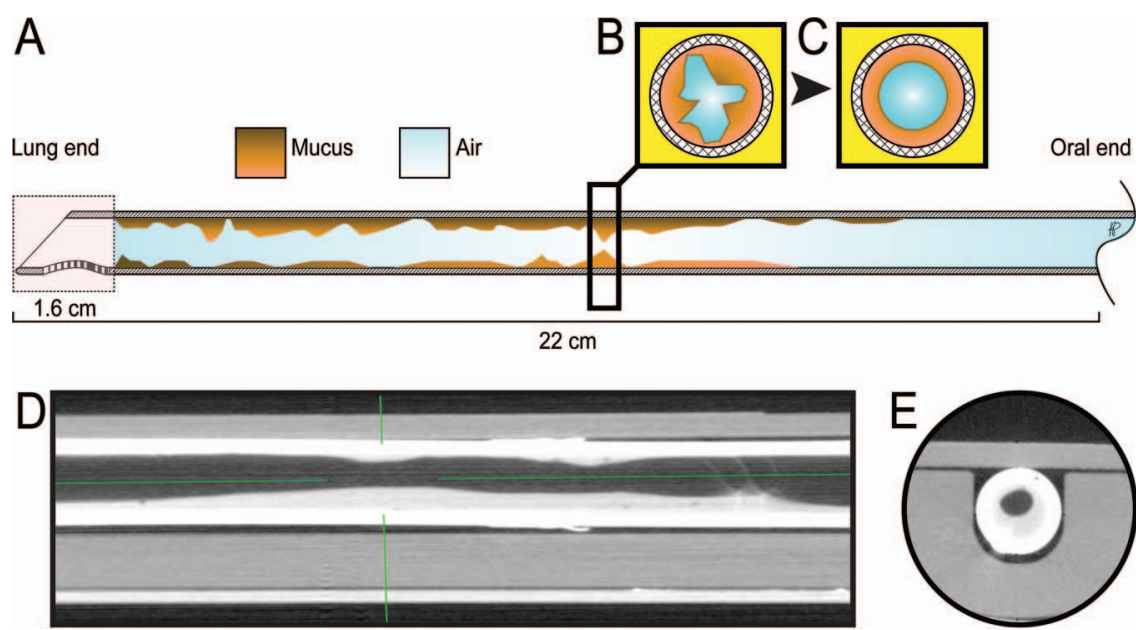

Fig. 2. High-resolution computed tomography image revealing biofilm buildup inside an endotracheal tube. From Reference 55.

problems largely because they are difficult to diagnose and often fail to respond to antimicrobial therapy. ${ }^{53}$

Devices Used to Remove Biofilm. Efforts have been made to develop devices that clear ETTs of secretions and biofilms (Fig. 2). In 2012, Berra et al ${ }^{54}$ evaluated the $\mathrm{Mu}-$ cus Shaver, a device designed to remove secretions from an ETT. They enrolled 24 subjects into their study; subjects were randomly assigned to a standard suction group $(n=12)$ or to a tube-scraping plus standard suction group $(n=12)$. At extubation, they noted that 1 of 12 ETTs were colonized in the device group versus 10 of 12 ETTs in the suction-only group (8\% vs $83 \%$, respectively, $P<.001$ ). The authors concluded that the tube-scraping device was helpful in preventing ETT colonization of potentially harmful microorganisms. ${ }^{54}$ They also noted that the device was safe and efficient in terms of ETT cleaning. ${ }^{54}$

In 2016, Pinciroli et $\mathrm{al}^{55}$ evaluated the endOclear device (endOclear LLC, San Ramon, California) (Fig. 3), which is also used to clear the inside of an ETT. ${ }^{56}$ They sought to evaluate the impact of a tube-scraping device on ETT occlusion due to mucus accumulation and bacterial colonization of the airway. They found that the device did reduce mucus accumulation and overall occlusion by a statistically significant amount. The clinical importance of this finding is questionable, however, because there was no correlation between length of intubation and ratio of ETT occlusion. In terms of bacterial colonization of tubes, it was associated with a 6-fold increase in ETTs that contained no bacteria. Also, known VAP-causing microorganisms were 50\% less likely to be found in ETTs cleaned with this device. ${ }^{55}$ It should be noted that although these results did show a trend toward reduced ETT microorganisms, these results were not statistically significant..$^{55} \mathrm{In}$ another study evaluating the effects of the same device on biofilm in ETTs, Bardes et al ${ }^{51}$ collected 40 ETTs at ex-

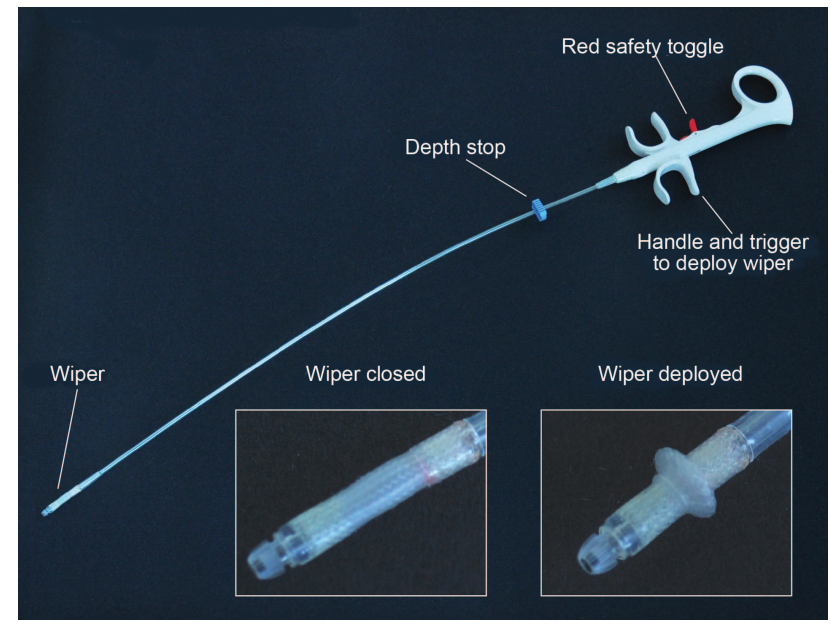

Fig. 3. The endOclear endotracheal tube cleaning device. From Reference 56.

tubation. Half of the ETTs were treated daily with the device, and biofilms were quantified from a standard point on the distal end of each tube. Interestingly, pneumonia was diagnosed in the device group $(n=11)$ more often than the control group $(n=6)$, but this difference did not reach statistical significance $(P=.36){ }^{51}$

Devices that remove biofilm from the inside of the ETT appear to be safe and effective at reducing luminal narrowing, airway resistance, and occlusion from secretions. ${ }^{55,57}$ However, their role in the prevention of VAEs has not yet been demonstrated.

\section{Subglottic Secretion Drainage}

Subglottic drainage has also been recommended to prevent VAEs by minimizing and removing the accumulation of secretions from above the ETT cuff. ${ }^{58}$ Removal of these 


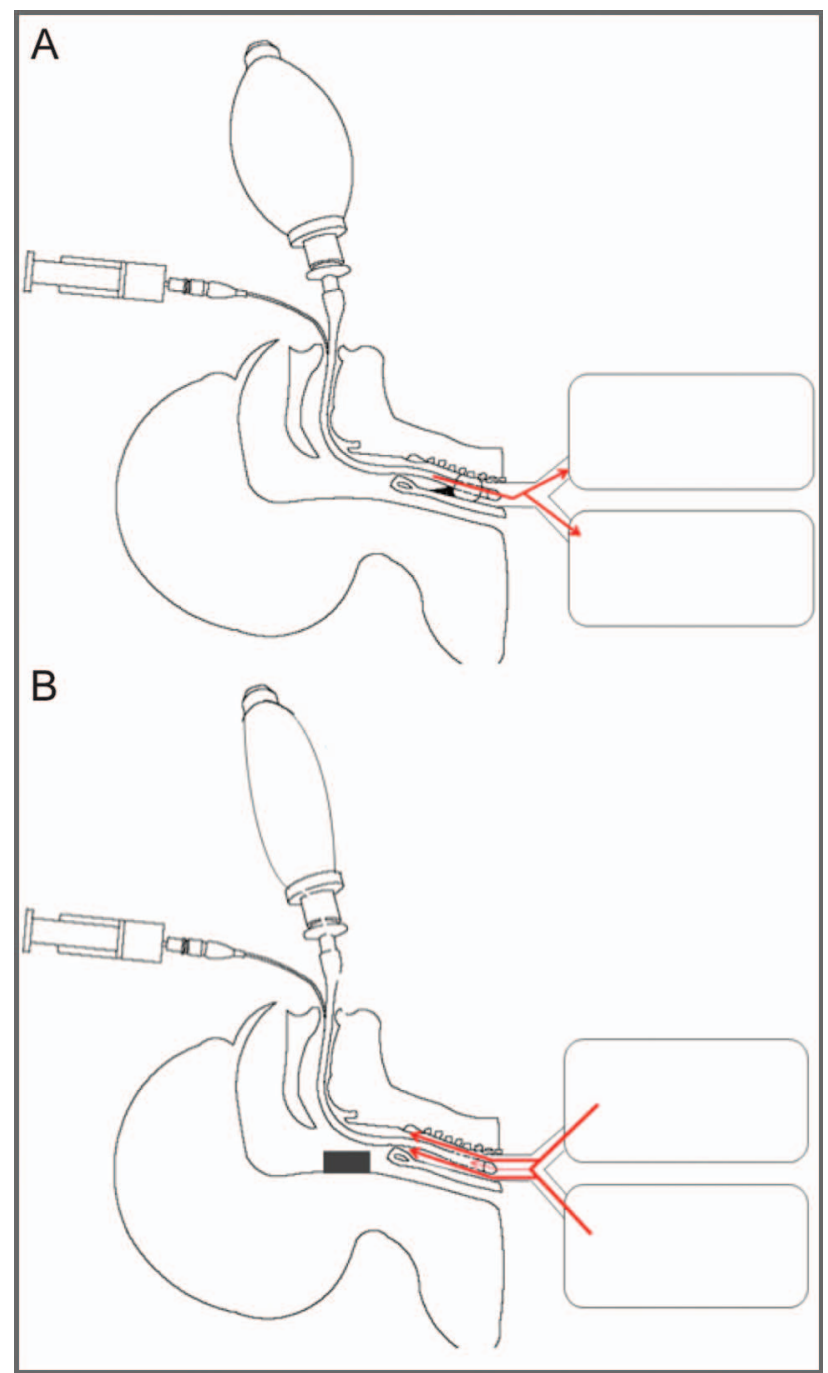

Fig. 4. Rapid flow expulsion maneuver to clear subglottic secretions. From Reference 60.

secretions is thought to reduce microaspiration of secretions that may lead to VAEs. Drainage of subglottic secretions from specialty ETTs is associated with lower VAP rates but has yet to demonstrate significant reductions in other important measures such as time on mechanical ventilation, duration of ICU stay, and mortality. ${ }^{27,58}$ Subglottic secretion drainage with specialty tubes can also be quite challenging. Exchanging a conventional ETT with an ETT with subglottic drainage (if not placed initially) can be risky. The suction port of ETTs with subglottic drainage abilities can become occluded by secretions or tracheal mucosa, which hinders subglottic secretion drainage and results in mucosal damage.,59

Recently, alternative methods to clear secretions have been described. $\mathrm{Li}$ et al ${ }^{60}$ evaluated the safety and effectiveness of a rapid-flow expulsion maneuver developed to clear subglottic secretions (Fig. 4). Their study consisted of both in vitro and in vivo analysis of the maneuver to assess secretion clearance from above an ETT cuff. The authors concluded that their maneuver was effective at clearing the majority of secretions above an ETT cuff during the first maneuver. They noted that patient position (ie, supine) and high peak flows influenced the efficiency of secretion removal. ${ }^{60}$ The limitation to this method is that it relies on practitioner skill and understanding of the procedure, and at least 2 clinicians are required to perform the maneuver. ${ }^{59,60}$

Other attempts at creating an effective artificial cough to clear secretions have been made. Zanella et al ${ }^{61}$ recently introduced a prototype device that synchronizes with a ventilator to remove secretions from below the ETT cuff by way of an artificial cough. Although this device is intriguing due to its ability to synchronize lung expansion and cuff management, their study did not evaluate the removal of secretions above the ETT cuff. It does demonstrate however, that artificial cough maneuvers can be produced without practitioner coordination. Further studies evaluating the effectiveness and impact of artificial cough maneuvers on VAEs are warranted.

\section{Optimizing Cuff Pressures}

ETT cuff-pressure management is a major role of the respiratory therapist. Proper cuff management can be challenging because a clinician needs to have the cuff properly inflated to allow for positive pressure breaths to be delivered and to reduce the likelihood of aspiration. Typically, manual cuff-pressure management is done by a manometer, but this method is associated with cuff overinflation $\left(>30 \mathrm{~cm} \mathrm{H}_{2} \mathrm{O}\right)$ and underinflation $\left(<20 \mathrm{~cm} \mathrm{H}_{2} \mathrm{O}\right) .{ }^{62}$ Devices that allow for the continuous regulation of cuff pressures have been developed for the routine care of ETT and tracheal tube cuffs.

In 2011, Nseir et al ${ }^{62}$ conducted a prospective, randomized, controlled trial to evaluate a pneumatic device designed to provide continuous cuff control versus routine care. They enrolled 122 subjects and randomized them to the pneumatic-device group $(n=61)$ or to the routine-care group $(n=61)$. They found a significantly lower rate of abundant microaspirations (ie, tracheal aspirates being $>65 \%$ pepsin-positive) in the pneumatic-device group when compared to the routine-care group (18\% vs $46 \%$, $P=.002)$. Bacterial concentration in tracheal aspirates $\left(\right.$ mean \pm SD $1.6 \pm 2.4$ vs $3.1 \pm 3.7 \log _{10} \mathrm{cfu} / \mathrm{mL}, P=.01$ ) and VAP rates $(9.8 \%$ vs $26.2 \%, P=.032)$ were also significantly lower in the pneumatic-device group compared to the routine-care group. They concluded that continuous control of the cuff pressure can significantly decrease microaspiration of gastric contents. ${ }^{62}$ Lorente et al ${ }^{63}$ conducted a prospective observational study to compare VAP rates in a group of patients treated with either con- 
tinuous or intermittent control of ETT cuff pressure. They found a lower incidence of VAP in the continuous control group $(n=150)$ compared to the intermittent control group $(n=134), 22 \%$ versus $11.2 \%$, respectively $(P=.02)$.

In a recent in vitro study, Aeppli et al ${ }^{64}$ showed that simply connecting and disconnecting a manometer from the pilot balloon can lead to a drop in ETT cuff pressure. They used an artificial trachea intubated with an ETT set at a cuff pressure of $20 \mathrm{~cm} \mathrm{H}_{2} \mathrm{O}$. Thirty-two experienced ICU nurses performed 6 cuff-pressure control maneuvers; 190 valid data sets of maneuvers were analyzed. In all 190 maneuvers, the cuff pressure dropped below $20 \mathrm{~cm} \mathrm{H}_{2} \mathrm{O}$ for at least 4 s. In 38 (20\%) of the maneuvers, the cuff pressure dropped below $10 \mathrm{~cm} \mathrm{H}_{2} \mathrm{O}$ for a duration of $3.7 \mathrm{~s}$. In 189 of the maneuvers, the initial connection of the manometer caused a cuff-pressure drop. Disconnection also caused the cuff pressure to drop in $75(78.1 \%)$ of the maneuvers. This study suggests that manual cuff-pressure maneuvers could lead to silent aspiration of secretions above the cuff of an artificial airway.

\section{Conclusions}

VAEs continue to be a cause of significant morbidity and mortality in critically ill patients. Airway management strategies aimed at reducing VAE rates may improve outcomes and costs associated with mechanical ventilation. Although closed-suction systems are recommended, their value lies in reducing complications associated with disconnection from mechanical ventilation, like alveolar derecruitment. Additionally, the routine use of normal saline is not recommended during suctioning, and may actually be considered harmful. Devices designed to remove secretions from the inside of ETTs appear to be safe and effective, but their role in reducing VAEs is still not clear. Artificial cough maneuvers that reduce subglottic secretions may be a future strategy, but these methods require further study. Other airway management practices, like continuous cuff-pressure management, show real promise in the reduction of VAEs in patients with artificial airways. VAE literature must continue to evolve to address effective and cost-efficient airway management practices.

\section{REFERENCES}

1. Diaz E, Rodríguez AH, Rello J. Ventilator-associated pneumonia: issues related to the artificial airway. Respir Care 2005;50(7):900-909.

2. Bonten MJM, Kollef MH, Hall JB. Risk factors for ventilator-associated pneumonia: from epidemiology to patient management. Clin Infect Dis 2004;38:1141-1149.

3. Letchford E, Bench S. Ventilator-associated pneumonia and suction: a review of the literature. Br J Nurs 2018;27(1):13-18.

4. Esteban A, Anzueto A, Frutos F, Brochard L, Stewart TE, Benito S, et al. Characteristics and outcomes in adult patients receiving mechanical ventilation: a 28-day international study. JAMA 2002;287: 345-55.
5. Rouze. A, Martin-Loeches I, Nseir S. Airway devices in ventilatorassociated pneumonia pathogenesis and prevention. Clin Chest Med 2018;39(4):775-783.

6. Hunter JD. Ventilator associated pneumonia. BMJ 2012;344:e3325.

7. Torres A, Ewig S, Lode H, Carlet J. Defining, treating and preventing hospital acquired pneumonia: European perspective. Intensive Care Med 2009;35:9-29.

8. Magill SS, Fridkin SK. Improving surveillance definitions for ventilator-associated pneumonia in an era of public reporting and performance measurement. Clin Infect Dis 2012;54(3):378-380.

9. Magill SS, Klompas M, Balk R, Burns SM, Deutschman CS, Diekema $\mathrm{D}$, et al. Developing a new, national approach to surveillance for ventilator-associated events. Crit Care Med 2013;41(11):2467-2475.

10. Horan TC, Andrus M, Dudeck MA. CDC/NHSN surveillance definition of health care-associated infection and criteria for specific types of infections in the acute care setting. Am J Infect Control 2008;36(5):309-332.

11. American Thoracic Society Board of Directors, IDSA Guideline Committee. Guidelines for the management of adults with hospitalacquired, ventilator-associated, and healthcare-associated pneumonia. Am J Respir Crit Care Med 2005;171:388-416.

12. Kalanuria AA, Zai W, Mirski M. Ventilator-associated pneumonia in the ICU. Crit Care 2014;18:208.

13. Tablan OC, Anderson LJ, Besser R, Bridges C, Hajjeh R, Healthcare Infection Control Practices Advisory Committee, et al. Guidelines for preventing health-care-associated pneumonia, 2003: recommendations of the CDC and the Healthcare Infection Control Practices Advisory Committee. MMWR Recomm Rep 2004;53(RR-3):1-36.

14. Rea-Neto A, Youssef NC, Tuche F, Brunkhorst F, Ranieri VM, Reinhart K, et al. Diagnosis of ventilator-associated pneumonia: a systematic review of the literature. Crit Care 2008;12(2):R56.

15. Centers for Disease Control and Prevention. Ventilator-associated event (VAE). 2019;10:1-45.

16. Klein Klouwenberg PM, Ong DS, Bos LD, de Beer FM, van Hooijdonk RT, Huson MA, et al. Interobserver agreement of Centers for Disease Control and Prevention criteria for classifying infections in critically ill patients. Crit Care Med 2013;41:2373-2378.

17. Stevens JP, Kachniarz B, Wright SB, Gillis J, Talmor D, Clardy P, et al. When policy gets it right: variability in U.S. hospitals' diagnosis of ventilator-associated pneumonia. Crit Care Med 2014;42: 497-503.

18. Melsen WG, Rovers MM, Groenwold RH, Bergmans DC, Camus C, Bauer TT, et al. Attributable mortality of ventilator-associated pneumonia: a meta-analysis of individual patient data from randomized prevention studies. Lancet Infect Dis 2013;13:665-671.

19. Centers for Disease Control and Prevention. Ventilator-associated events (VAE) surveillance for adults special edition. NHSN e-News: 2012. Available at: https://www.cdc.gov/nhsn/pdfs/newsletters/vaenewsletter-september2012.pdf. Accessed January 2019.

20. Klompas M, Khan Y, Kleinman K, Evans RS, Lloyd JF, Stevenson K, et al. Multicenter evaluation of a novel surveillance paradigm for complications of mechanical ventilation. PLoS One 2011;6(3):e18062.

21. Klompas M. Ventilator-associated events surveillance: a patient safety opportunity. Curr Opn Crit Care 2013;19(5):424-431.

22. Neuville M, Mourvillier B, Bouadma L, Timsit JF. Bundle of care decreased ventilator-associated events- implications for ventilatorassociated pneumonia prevention. J Thorac Dis 2017;9(3):430-433.

23. Klompas M, Magill S, Robicsek A, Strymish JM, Kleinman K, Evans RS, et al. Objective surveillance definitions for ventilator-associated pneumonia. Crit Care Med;2012:3154-61.

24. Klompas M, Anderson D, Trick W, Babcock H, Kerlin MP, Li L, et al. The preventability of ventilator-associated events. The CDC prevention epicenters wake up and breathe collaboration. Am J Respir Crit Care Med 2015;191(3):292-301. 
25. Klompas M. Complications of mechanical ventilation: the CDC's new surveillance paradigm. N Engl J Med 2013;368:1472-1475.

26. Coppadoro A, Bittner E, Berra L. Novel preventive strategies for ventilator-associated pneumonia. Crit Care 2012;16:210.

27. Cocoros NM, Klompas M. Ventilator-associated events and their prevention. Infect Dis Clin N Am 2016;30(4):887-908.

28. Wunsch H, Linde-Zwirble WT, Angus DC, Harman ME, Milbrandt EB, Kahn JM. The epidemiology of mechanical ventilation use in the United States. Crit Care Med 2010;38(10):1947-1953.

29. Safdar N, Crnich CJ, Maki DG. The pathogenesis of ventilatorassociated pneumonia: its relevance to developing effective strategies for prevention. Respir Care 2005;50(6):725-741.

30. Muscedere J, Dodek P, Keenan S, Fowler R, Cook D, Heyland D, et al. Comprehensive evidence-based clinical practice guidelines for ventilator-associated pneumonia: prevention. J Crit Care 2008;23: 126-137.

31. Behrendt CE. Acute respiratory failure in the United States: incidence and 31-day survival. Chest 2000;118(4):1100-1105.

32. Kahn JM, Goss CH, Heagerty PJ, Kramer AA, O'Brien CR, Rubenfeld GD. Hospital volume and the outcomes of mechanical ventilation. N Engl J Med 2006;355(1):41-50.

33. Kallet RH. The vexing problem of ventilator-associated pneumonia: observations on pathophysiology, public policy, and clinical science. Respir Care 2015;60(10):1495-1508.

34. Chastre J, Fagon JY. Ventilator-associated pneumonia. Am J Respir Crit Care Med 2002;165(7):867-903.

35. Dodek P, Keenan S, Cook D, Heyland D, Jacka M, Hand L, et al. Evidence-based clinical practice guideline for the prevention of ventilator-associated pneumonia. Ann Intern Med 2004;141:305-313.

36. O'Grady NP, Murray PR, Ames N. Preventing ventilator-associated pneumonia: does the evidence support the practice? JAMA 2012; 307(23):2534-2539.

37. Boyer AF, Schoenberg N, Babcock H, McMullen KM, Micek ST, Kollef MH. A prospective evaluation of ventilator-associated conditions and infection-related ventilator-associated conditions. Chest 2015;147(1):68-81.

38. Klompas M, Kleinman K, Murphy MV. Descriptive epidemiology and attributable morbidity of ventilator-associated events. Infect Control Hosp Epidemiol 2014;35(5):502-510.

39. Muscedere J, Sinuff T, Heyland DK, Dodeck PM, Keenan SP, Wood $\mathrm{G}$, et al. The clinical impact and preventability of ventilator-associated conditions in critically ill mechanically ventilated patients. Chest 2013;144(5):1453-1460.

40. Warren DK, Shulka SJ, Olsen MA, Kollef MH, Hollenbeak CS, Cox MJ, et al. Outcome and attributable cost of ventilator-associated pneumonia among intensive care unit patients in a suburban medical center. Crit Care Med 2003;31(5):1312-1317.

41. Zimlichman E, Henderson D, Tamir O, Franz C, Song P, Yamin CK, et al. Health care-associated infections: a meta-analysis of costs and financial impact on the US health care system. JAMA Intern Med 2013;173(22):2039-2046.

42. Mietto C, Pinciroli R, Patel N, Berra L. Ventilator-associated pneumonia: evolving definitions and preventative strategies. Respir Care 2013;58(6):990-1007.

43. Branson RD, Gomaa D, Rodriquez D. Management of the artificial airway. Respir Care 2014;59(6):974-990.

44. Stoller JK, Orens DK, Fatica C, Elliott M, Kester L, Woods J, et al. Weekly versus daily changes of in-line suction catheters: impact on rates of ventilator-associated pneumonia and associated costs. Respir Care 2003;48(5):494-499.

45. Zeitoun SS, De Barros ALBL, Diccini S. A prospective, randomized study of ventilator-associated pneumonia in patients using a closed vs. open suction system. J Clin Nurs 2003;12:484-489.
46. American Association of Respiratory Care. AARC clinical practice guidelines: endotracheal suctioning of mechanically ventilated patients with artificial airways 2010. Respir Care 2010;55(6):758-764.

47. Maggiore SM, Lellouche F, Pignataro C, Girou E, Maitre B, Richard JM, et al. Decreasing the adverse effects of endotracheal suctioning during mechanical ventilation by changing practice. Respir Care 2013;58(10):1588-1597.

48. David D, Samuel P, David T, Keshava SN, Irodi A, Peter JV. An open-labelled randomized controlled trial comparing costs and clinical outcomes of open endotracheal suctioning with closed endotracheal suctioning in mechanically ventilated medical intensive care patients. J Crit Care 2011;26(5):482-488.

49. Caparros ACS, Forbes A. Mechanical ventilation and the role of saline instillation in suctioning adult intensive care unit patients. Dimens Crit Care Nurs 2014;33(4):246-253.

50. Wang CH, Tsai JC, Chen SF, Su CL, Chen L, Lin CC, et al. Normal saline instillation before suctioning: a meta-analysis of randomized controlled trials. Aust Crit Care 2017;30:260-265.

51. Bardes JM, Gray D, Wilson A. Effect of the endOclear ${ }^{\circledR}$ device on biofilm in endotracheal tubes. Surg Infect 2017;18(3):293-298.

52. Kumar A, Alam A, Rani M, Ehtesham NZ, Hasnain SE. Biofilms: survival and defense strategy for pathogens. Int J Med Microbiol 2017;207(8):481-489.

53. Boisvert AA, Cheng MP, Sheppard DC, Nguyen D. Microbial biofilms in pulmonary and critical care diseases. Ann Am Thorac Soc 2016;13(9):1615-1623

54. Berra L, Coppadoro A, Bittner EA, Kolobow T, Laquerriere P, Pohlmann JR, et al. A clinical assessment of the Mucus Shaver: a device to keep the endotracheal tube free from secretions. Crit Care Med 2012;40(1):119-124.

55. Pinciroli R, Mietto C, Piriyapatsom A, Chenelle CT, Thomas JG, Pirrone M, et al. Endotracheal tubes cleaned with a novel mechanism for secretion removal: a randomized controlled clinical study. Respir Care 2016;61(11):1431-1439.

56. Mietto C, Foley K, Salerno L, Oleksak J, Pinciroli R, Goverman J, Berra L. Removal of endotracheal tube obstruction with a secretion clearance device. Respir Care 2014;59(9):e122-e126.

57. Scott JB, Dubosky MN, Vines DL, Sulaiman AS, Jendral KR, Singh $\mathrm{G}$, et al. Evaluation of endotracheal tube scraping on airway resistance. Respir Care 2017;62(11):1423-1427.

58. Caroff D, Li L, Muscedere J, Klompas M. Subglottic secretion drainage and objective outcomes: a systematic review and meta-analysis. Crit Care Med 2016;44(4):830-840.

59. Li J, Scott JB, Luo J, Dai H, Wang C. Artificial cough maneuvers: a new method of secretion clearance? (editorial). Respir Care 2019; 64(4):487-488

60. Li J, Zong Y, Zhou Q, Dai H, Wang C. Evaluation of the safety and effectiveness of the rapid flow expulsion maneuver to clear subglottic secretions in vitro and in vivo. Respir Care 2017;62(8):10071013.

61. Zanella A, Florio G, Rezoagli E, Pastore M, Cadringer P, Biancolilli $\mathrm{O}$, et al. An artificial cough maneuver to remove secretions from below the endotracheal tube cuff. Respir Care 2019;64(4):372-383.

62. Nseir S, Zerimech F, Fournier C, Lubret R, Ramon P, Durocher A, et al. Continuous control of tracheal cuff pressure and microaspiration of gastric contents in critically ill patients. Am J Respir Crit Care Med 2011;184(9):1041-1047.

63. Lorente L, Lecuona M, Jiménez A, Lorenzo L, Roca I, Cabrera J, et al. Continuous endotracheal tube cuff pressure control system protects against ventilator-associated pneumonia. Crit Care 2014;18(2):R77.

64. Aeppli N, Lindauer B, Steurer MP, Weiss M, Dullenkopf A. Endotracheal tube cuff pressure changes during manual cuff pressure control manoeuvres: an in-vitro assessment. Acta Anaesthesiol Scand 2019;63(1):55-60. 